\title{
Stressed Out Schools: Correlations Between Stress Coping Strategies and Communities Among Youth in Seattle and Surrounding Regions
}

\author{
Nithya Kemp* \\ Newport High School, Bellevue, United States of America
}

\begin{abstract}
Researchers have observed differences in stress levels, and coping abilities and mechanisms based on the community being studied. This paper reports on the impact of extracurricular activities and student communities on stress and coping for youth in the Seattle area. Various self-reports, distributed through school health teachers, were used to gain information on students' stress levels, coping mechanisms, and coping ability. Results indicate that general categorizations of communities and activities (music, sports, etc.) did not demonstrate a significant correlation with students' stress or coping levels. Correlations between stress and coping were found, as were correlations between stress and coping and the number of communities/activities that students were involved in. Results provide insight into how students' activity loads impact their stress and coping levels more than the specific activities they are involved in and open the door to further research in the field.
\end{abstract}

Keywords: Activities, anxiety, clubs, communities, community, cope, coping, coping ability, coping mechanisms, depression, drugs, extracurricular activity, health, mental health, music, perceived stress, school, sports, stress, teen, teenager, vape, volunteering, youth

\section{Introduction}

Approximately $20 \%$ of adolescents have a diagnosable mental illness and a quarter of individuals with mood disorders are shown to have had their disorders since adolescence [1]. The prevalence of mental health issues among youth in the United States is an issue that has often been ignored despite continuing research on the subject and related statistics. Discussions about stressors and mental health are sometimes discussed at school events or in occasional Social Emotional Learning (SEL) sessions lead by the Bellevue School District, based in the Seattle Area [2]. Although the lessons indicate progressive awareness on youth stress, this transition is recent and pays closer attention to preventing youth from attaining high levels of stress rather than handling it. Stressors are defined by the American Psychological Association as "any event, force, or condition that results in physical or emotional stress" [3]. There is a lack of information on what kinds of stress-relieving coping mechanisms students use and whether adolescents tend to lean toward one type of coping mechanism or another. An especially noticeable gap lies in what factors influence potential trends in stress-relieving, coping mechanisms. Coping mechanisms or strategies "refer to the specific efforts, both behavioral and psychological, that people employ to master, tolerate, reduce, or minimize stressful events" [4]. As there is potential for differences between students based on extracurricular activities, identifying which communities of students are worse than others at coping with their stress allows for more accurate interventions to help students learn how to cope with their stress.

\section{Literature Review}

\section{A. Correlations Between Trauma and Coping}

Prior to investigation, a deeper understanding of the body of knowledge is required. A trend among papers addressing youth stress and coping deal with trauma-specific coping and violence-specific coping. Cherewick et al. investigated the cognitive and behavioral coping mechanisms of traumaaffected youth in the Eastern Democratic Republic of Congo and found that cognitive strategies among these youth included forgetting and praying, while behavioral mechanisms included acquiring social support and participating in risk-taking behaviors such as substance abuse [5]. Vaughn-Coaxum et al. take a crucial step in identifying coping strategies of traumaaffected youth by separating the mechanisms into positive and negative and then identifying correlations [6]. The researchers addressed the effect of trauma on the development of coping mechanisms on youth and found that there was a negative correlation between trauma and "negative emotion-focused coping," which includes physical mechanisms such as yelling and crying as well as mental mechanisms such as ruminating on negative thoughts. They found no correlation between trauma and "positive emotion-focused coping" behaviors such as writing about one's emotions or mindful meditation [6]. Prior to Vaughn-Coaxum et al.'s and Cherwick et al.'s research, Boxer et al. investigated these strategies on youth's mental 
health symptoms [7]. More specifically, Boxer et al. took note of a relationship between what they call "externalizedinternalized strategies," which are akin to Vaughn-Coaxum et al.'s physical examples of "negative emotion-focused behaviors"-yelling and crying - and negative mental health symptoms, but noted that there was a lack of correlation between internal coping mechanisms, such as pretending nothing happened, and mental health symptoms, concluding that not all negative coping is uniformly associated with negative mental health outcomes for youth [6], [7].

\section{B. Internalizing and Externalizing Symptoms}

In reviewing the literature, Boxer et al.'s use of "externalized-internalized strategies" was common and explores the contrast between internalizing and externalizing symptoms and behaviors. These symptoms are "key indicators of psychopathology that can be assessed through parent report across the lifespan" and their presence throughout childhood and adolescence can result in an increased risk of "psychiatric diagnoses" in adulthood [8]. Internalizing symptoms may include anxiety, depression, fear, and social withdrawal while externalizing symptoms include aggression, rule-breaking behavior, and lack of self-restraint [8]. One study by Rosenberg et al. analyzes the effects of self-theory, how an individual views themselves, on internalizing and externalizing symptoms and behaviors when coping with emotional and behavioral issues [9]. Overall, that study observed that the associations between self-theory and ability to cope were stronger among adolescents than among emerging adults [9]. While that paper observed differences in age, Rosario et al.'s work indicates differences between genders in their study which outlines coping and social support for youth who have been exposed to community violence [10]. The study's focus was on the effects of social support and coping on internalizing symptoms for urban youth who had experienced community violence. Findings indicated that boys were more likely to increase their use of defensive or confrontational coping, while girls experienced more support within two years of the traumainducing experience [10]. Gaylord-Harden and Cunningham focused on internalizing symptoms in their study that addressed the effects of racial discrimination on African American youth and their coping strategies and internalizing symptoms [11]. Results indicated that discrimination was positively associated with depression and anxiety [11].

\section{Race and Socio-Economic Status with Respect to Coping}

One aspect of Gaylord-Harden and Cunningham's research is the theory that ethnic background influences coping mechanisms. This phenomenon has been observed and researched by others in the field as well. Sanchez et al. specifically address African American youth in a low-income urban setting [12]. The paper focuses on the effects of negative life events on the coping mechanisms of these youth. The results indicate that violent experiences were associated with externalizing behavior while economic stress and discrimination correlated with internalizing behavior along with a gender variation in coping strategies. Jose and
Huntsinger address two different socio-ethnic groups within the United States in their study [13]. Specifically, they look at Chinese American and European American adolescents and observed the effects of various coping mechanisms on these youth. Overall, problem-focused and avoidance-coping among Chinese American youth demonstrated moderating effects, but this was not the case for European American youth [13]. This study varied from much of the previous literature in that it focused on a specific life condition, grades, in respect to coping mechanisms and stress rather than overall negative life conditions and events or traumatic experiences. Jose and Huntsinger's work varies from other papers in both its test subjects, Chinese American and European American youth, as well as its primary independent variable, grades, and therefore addresses what had previously been a gap, especially through their comparison between the two demographics. However, not much work has been done to maintain age as a constant and using a wider range of identities as factors or, in other words, analyzing the variations among youths' stressors and coping mechanisms based primarily off of their communities.

So, the question arises, does a youth's community influence their life stressors and ability to cope? In this paper, I seek to address this issue and find disparities based on adolescents' communities. I define "community" for this study as the extracurricular activities a student is involved in that influence who they spend time with and what groups they are part of. Based on the literature, I believe I will find that those who are involved in more extracurricular activities and thus are part of more communities spend more time socializing and thus tend toward more social and interactive coping mechanisms than those who do not. They will also be worse at managing their stress because they have less time to do so. I believe that students in certain communities will tend to do some activities more than other groups (e.g. members of music communities will play music more relative to students involved in sports communities) at a measurable scale.

\section{Methods}

\section{A. Participants}

Participants came from two high schools in the Seattle area. Of the participants, $48 \%$ identify as female, $48 \%$ identify as male, $1 \%$ identify as non-binary, and $2 \%$ as other. The participants identified as $60 \%$ White or Caucasian, $19 \%$ Asian or Pacific Islander, 7\% Latino, 4\% African American, and the remaining identified as either mixed or some combination of the previous categories. Socio-economically, $9 \%$ self-identified as "upper" class, 69\% identified as "upper-middle," $20 \%$ identified as "lower-middle," and $2 \%$ identified as "lower" class. An overwhelming majority of survey respondents were high school freshman (82\%), while 13\% were sophomores, $4 \%$ seniors, and one identified as not attending school.

\section{B. Procedures}

I used an online survey (Appendix A), which was distributed to 141 high school students in the Seattle area. A survey provided the most efficient method to gather trends in a large 
Table 1

\begin{tabular}{|c|c|c|c|}
\hline Demographics & Frequency (\%) & Demographics & Frequency (\%) \\
\hline $\begin{array}{l}\text { Gender } \\
\quad \text { Female } \\
\text { Male } \\
\text { Non-Binary } \\
\text { Prefer Not to Say }\end{array}$ & $\begin{array}{l}48 \\
48 \\
2 \\
2\end{array}$ & $\begin{array}{l}\text { Income Range } \\
\text { Lower } \\
\text { Lower-middle } \\
\text { Upper-middle } \\
\text { High }\end{array}$ & $\begin{array}{l}2 \\
20 \\
68 \\
8\end{array}$ \\
\hline Age & \multirow{3}{*}{$\begin{array}{l}1 \\
44 \\
43 \\
9 \\
2 \\
0 \\
1\end{array}$} & Blank & 2 \\
\hline $\begin{array}{l}13 \\
14 \\
15 \\
16\end{array}$ & & $\begin{array}{l}\text { Mental/Emotional Health } \\
\text { Previous Moderate to Severe } \\
\text { Mental/Emotional Challenges } \\
\text { Has a Diagnosable Mental Illness }\end{array}$ & $\begin{array}{l}45 \\
16\end{array}$ \\
\hline $\begin{array}{l}17 \\
18 \\
19\end{array}$ & & $\begin{array}{l}\text { Sexual Orientation/Self Identification } \\
\text { Straight } \\
\text { LGBT }\end{array}$ & $\begin{array}{l}80 \\
16\end{array}$ \\
\hline \multirow[b]{2}{*}{$\begin{array}{l}\text { Ethnicity } \\
\text { Caucasian/White } \\
\text { Asian/Pacific Islander } \\
\text { Black/African American } \\
\text { Hispanic/Latino } \\
\text { Native American/ } \\
\text { American Indian } \\
\text { Other }\end{array}$} & \multirow[b]{2}{*}{$\begin{array}{l}66 \\
2 \\
4 \\
9 \\
1\end{array}$} & Unsure & 4 \\
\hline & & $\begin{array}{l}\text { High School } \\
\text { School } 1 \\
\text { School } 2\end{array}$ & $\begin{array}{l}87 \\
13\end{array}$ \\
\hline
\end{tabular}

sample population of youth and provided quantitative data. A case study would have provided qualitative data to complement the data, but with my resources, this was not possible.

\section{Distribution}

I emailed the health teachers of 15 secondary schools and high schools in the Seattle area, including both private and public institutions. Two responded to my email and willingly distributed the survey. One health teacher required that students take the survey in class, the other allowed for more voluntary participation, encouraging her students to take the survey outside of class. As a result, the data leans more in quantity towards one school (87\%). As most of my observations of stress in a school setting occurred in my own school, I sought to include other schools in my study in an attempt to reduce potential bias. My rationale for contacting health teachers was that they were most likely to respond and be willing to participate as they teach their students material that is similar to what I am researching and, as health teachers, they would be most likely to understand the importance of my research to a greater depth than other teachers or administrators might. Furthermore, health is a mandatory class for students in every school in my area as it is required for graduation by the government. Students therefore come from nearly all possible groups and communities in the region making them the ideal survey population.

\section{Ethics}

Regarding the ethics of distributing a survey and performing research on humans, I allowed my respondents the choice of either taking the survey anonymously or including their name after signing a consent form (Appendix B). The first option was added to increase participation. In this manner, I ensured privacy was maintained if the survey-taker wished and that any user who attached their name to their data understood what that entailed by signing a form.

\section{E. Measures}

Since my study is aimed observing a relationship between an individual's community and their stress and coping mechanisms, I set a few constants as potential communities and compared them with coping mechanisms-grouped both individually and by what is positive and what is negative. The communities I tested for were sports, music, volunteering, and clubs. The coping mechanisms/categories I tested for to find a correlation were:

1. Mechanisms: exercise, do chores, use addictive drugs, work, do homework, listen to music, play music, cook, draw, vape, sing, use marijuana, drive, hang out with friends, spend time with family, eat, physically or verbally fight, isolate myself, stay alone in my room, get some space, watch something, binge eat, video games, and read something

2. Categories: Negative-which I categorized as potentially harming one's mental or physical health, providing only short term-benefits (yelling, crying, hitting, isolation, drug use); Positive — coping mechanisms that either lead to long-term benefits or do not indicate serious potential health issues (talking, listening to music); Externalverbally and/or physically involved coping methods (yelling, talking); Internal-independent or internalized methods (isolation, reading).

The first two categories listed are based on Vaughn-Coaxum et al.'s negative emotion-focused coping and positive emotionfocused coping while the last two build on Rosenberg et al.'s self-theory [1][9]. These measures are best because they consider generalization that, if shown to have a correlation with any community factors, can provide clear information on existing trends which could be used to better understand how teenagers cope with stress.

I used the Perceived Stress Scale to measure how stressed students were [14]. I created my own scale, the Coping Ability Scale, to measure the students' ability to cope with their stress. My scale was based on a scale used by similar studies on children [15], [16]. The higher the score on both of these tests, the more stressed or worse at coping someone is, respectively. These self-reports provided the most efficient way to record average stress levels and coping abilities, making it ideal for 


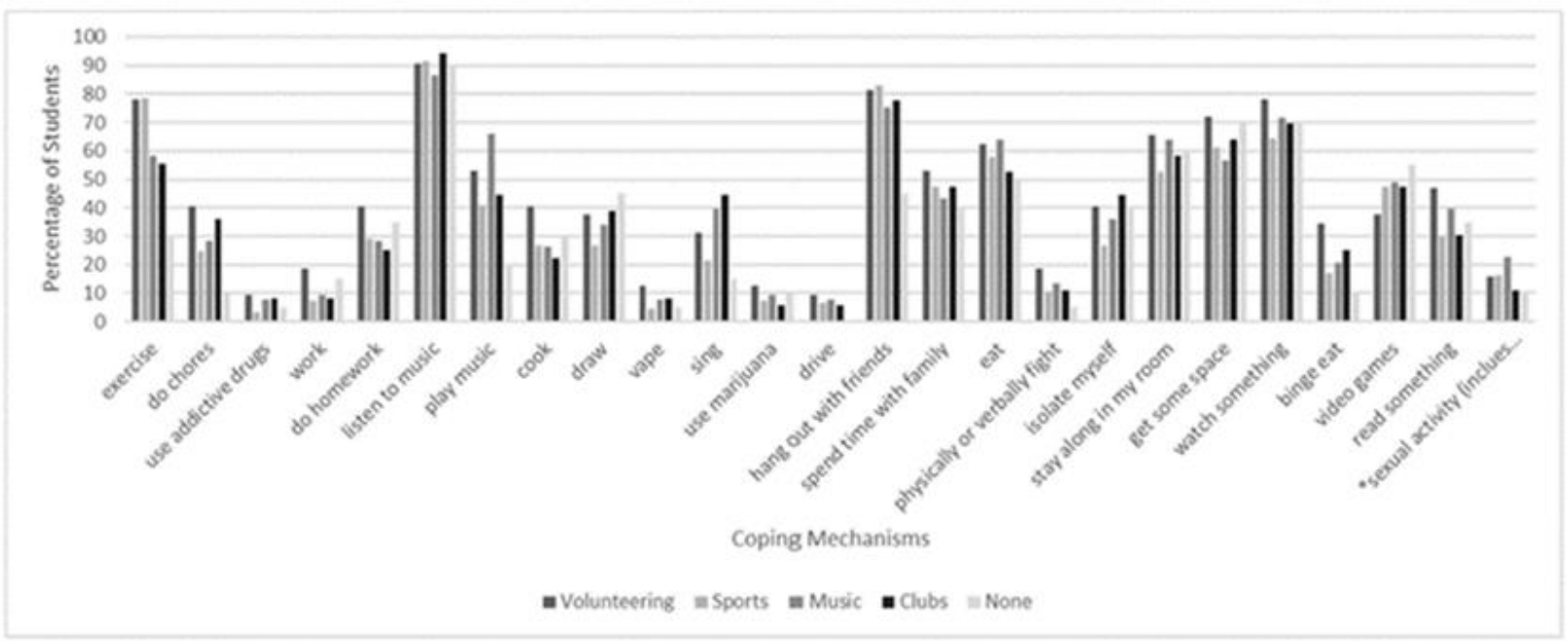

Fig. 1. Coping mechanism vs. Percentage of students

Table 2

\begin{tabular}{|l|l|l|l|l|l|}
\hline Activity & $\begin{array}{l}\text { Participates } \\
\text { in Activity }\end{array}$ & $\begin{array}{l}\text { AVG Stress } \\
\text { Level }\end{array}$ & $\begin{array}{l}\text { AVG Positive Coping } \\
\text { Mechanisms }\end{array}$ & $\begin{array}{l}\text { AVG Negative Coping } \\
\text { Mechanisms }\end{array}$ & $\begin{array}{l}\text { AVG Coping } \\
\text { Ability }\end{array}$ \\
\hline Volunteering & Does & 20.032 & 7.548 & 2.677 & 28.226 \\
\hline & Does Not & 19.855 & 5.791 & 2.1 & 27.518 \\
\hline & & & & & \\
\hline Sport & Does & 18.93478261 & 6.423913043 & 2.141304348 & 27.14130435 \\
\hline & Does Not & 21.69387755 & 5.714285714 & 2.387755102 & 28.67346939 \\
\hline & & & & & \\
\hline Music & Does & 21.86538462 & 6.75 & 2.461538462 & 29.46153846 \\
\hline & Does Not & 18.74157303 & 5.842696629 & 2.08988764 & 26.62921348 \\
\hline & & & & & 28.8 \\
\hline Clubs & Does & 21.17142857 & 6.4 & 2.4 & 27.30188679 \\
\hline & Does Not & 19.47169811 & 6.103773585 & 2.169811321 & \\
\hline & & & & & 27.88429752 \\
\hline Any Activity & Does & 20.00826446 & 6.289256198 & 2.223140496 & 26.4 \\
\hline & Does Not & 19.2 & 5.5 & 2.25 & \\
\hline
\end{tabular}

this study. Furthermore, some form of both have already been used in previous studies, producing fruitful results, indicating their validity as tools of measurement.

\section{Findings}

Table 1 provides a statistical outline for the 141 individuals involved in the study. The five categories for the sample population were whether they participated in volunteering or not, sports or not, music or not, clubs or not, and any of the previous activities or not.

A total of 32 students reported that they "volunteered," 93 reported that they participated in "sports," 53 reported that they participated in some sort of "music" program, 36 reported participating in "clubs," and 20 reported participating in none of these categories.

Figure 1 illustrates the frequency with which students who said that they were involved in "volunteering," "sport," "music," "clubs," or any of the previous activities, participate in each respective coping mechanism. A few of the notable trends from this chart: students who volunteer and participate in sports tend to "exercise" more to relieve stress than other groups; students who volunteer tend to "do chores," "work," "do homework," and "cook" more than other groups to relieve stress; students involved in music programs "play music" more often than other groups to relieve stress; students who are involved in sports "isolate [themselves]" less than other groups; around $90 \%$ of members of all groups "listen to music" to relieve stress; 70 to $80 \%$ of members of all groups "hang out with friends" to relieve stress; and around 50 to $60 \%$ of all groups "eat" to relieve stress.

I also examined the average number of positive and negative coping mechanisms of members of each group, as well as how they scored on average on the Perceived Stress Scale and the adapted Coping Ability Scale.

Table 2 shows the data while Figures 2 to 6 illustrate the data more visually. The Perceived Stress Scale ranges from a score of 0 being the least stressed to 40 being the most stressed. The Coping Ability Scale ranges from 0 being the best possible coper of stress and 64 being the worst possible coper of stress.

A few notable trends from the table and charts: there appears to be a difference of around 1 to 2 points in stress level and perceived coping ability between those who do participate in any given activity vs. those who do not, the exception is the sports category; categories with higher levels of stress also have higher levels of perceived coping ability (or are worse at handling their stress). 


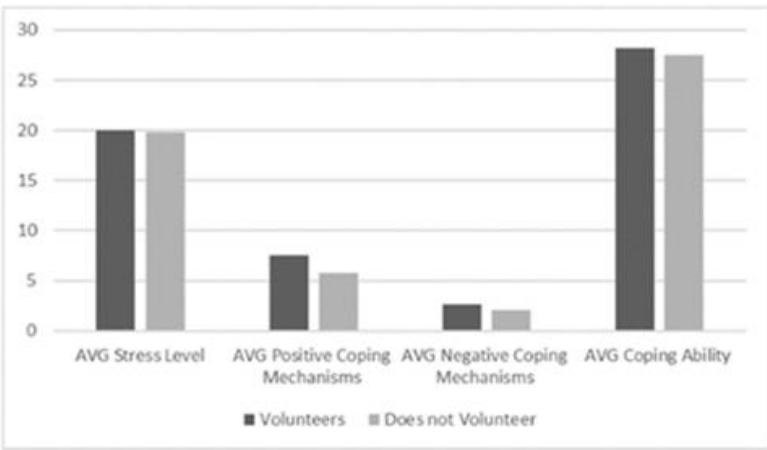

Fig. 2.

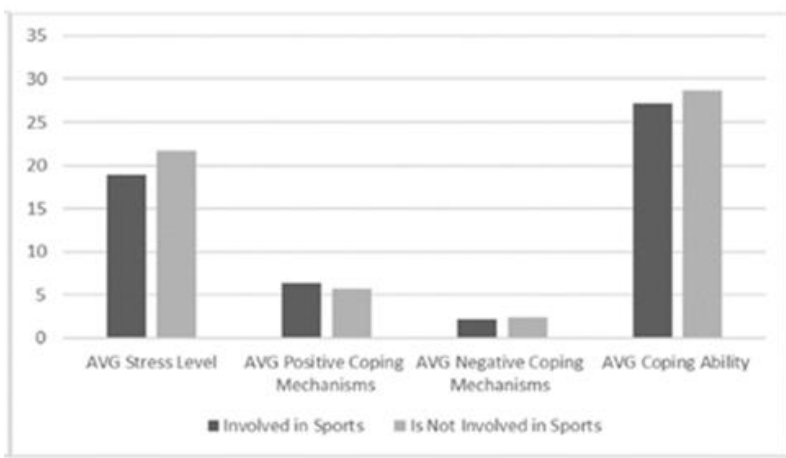

Fig. 3.

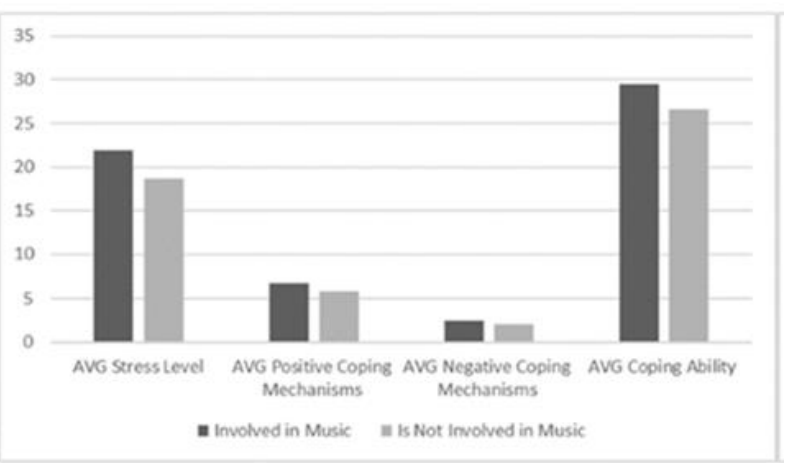

Fig. 4.

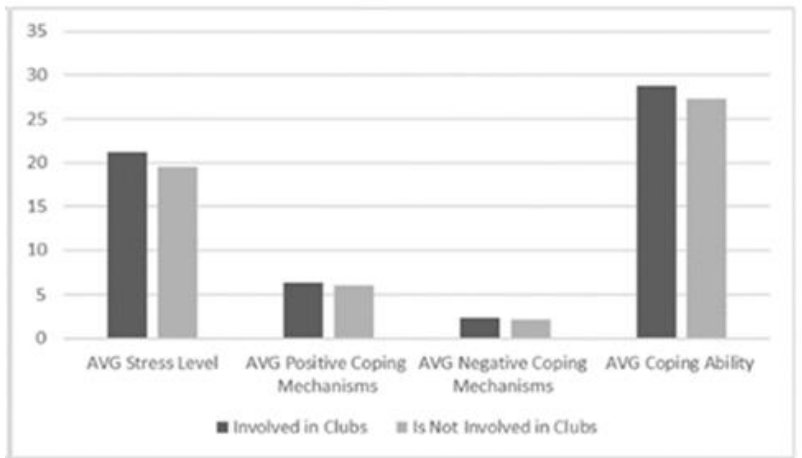

Fig. 5.

Table 3 and Figure 7 illustrate the findings for the number of extracurricular, the students are involved in. A notable trend: students involved in extracurriculars in all four categoriessports, volunteering, music, and clubs - experience far more stress and are reportedly far worse at handling their stress.

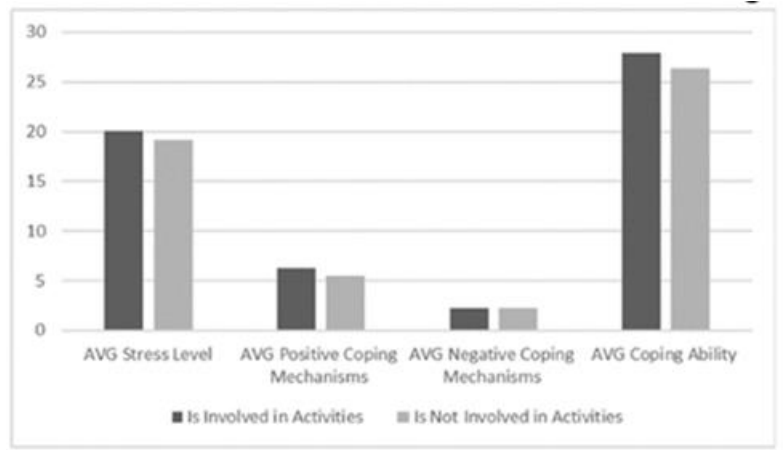

Fig. 6.

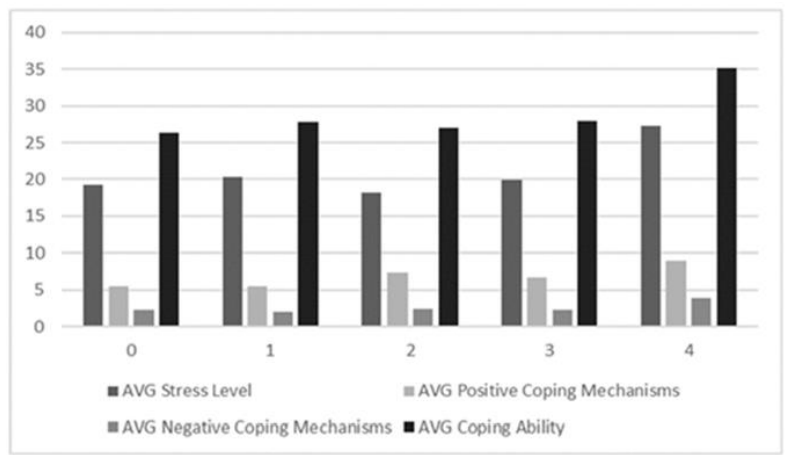

Fig. 7.

Table 3

\begin{tabular}{|l|l|l|l|l|}
\hline $\begin{array}{l}\text { Number of } \\
\text { Activities }\end{array}$ & $\begin{array}{l}\text { AVG Stress } \\
\text { Level }\end{array}$ & $\begin{array}{l}\text { AVG Positive Coping } \\
\text { Mechanisms }\end{array}$ & $\begin{array}{l}\text { AVG Negative Coping } \\
\text { Mechanisms }\end{array}$ & $\begin{array}{l}\text { AVG Coping } \\
\text { Ability }\end{array}$ \\
\hline 0 & 19.2 & 5.5 & 2.25 & 26.4 \\
\hline 1 & 20.33846154 & 5.523076923 & 2.046153846 & 27.86153846 \\
\hline 2 & 18.24137931 & 7.344827586 & 2.344827586 & 26.96551724 \\
\hline 3 & 19.95238095 & 6.714285714 & 2.333333333 & 27.95238095 \\
\hline 4 & 27.28571429 & 9 & 3.857142857 & 35.14285714 \\
\hline
\end{tabular}

\section{Discussion}

\section{A. Community Impact on Stressors and Stress Levels}

Hypothesis: Part 1. Those who are involved in more social extracurricular activities (volunteering, sports) spend more time socializing than other groups (music, clubs) and thus tend toward more social and interactive coping mechanisms than those who do not; Part 2. They will also be worse at managing their stress because they have less time to do so; Part 3. Students in certain communities will tend to do some activities more than others (e.g. members of music communities will play music more) at a measurable scale.

My findings suggest that Part 3 was correct, while the other two were not. Concerning Part 3, while certain small differences in coping mechanisms exist depending on the community, there are no overall themed trends that would be alarming.

Part 1:

Based on the data collected, those in more social extracurriculars, volunteering and sports, do not tend towards more social and interactive coping mechanisms than those who are not involved in them. Instead, those who are involved in a volunteer, sports, music, or club community use more social coping mechanisms on average than those who are part of none of those communities.

Social coping mechanisms include "hang out with friends," 
"spend time with family," and "physically or verbally fight."

As many as $81 \%$ of students who are part of a volunteering community "hang out with friends" to relieve stress, as do $83 \%$ of students who are part of a sports community, $75 \%$ of students who are part of a music community, and $78 \%$ of students who are part of a club community. Only $45 \%$ of students who are not part of any communities do so. The discrepancy indicates a significant difference between these two groups in who hangs out with friends to relieve their stress.

Similarly, 53\% of students who are part of a volunteering community "spend time with family" to relieve stress, as do $47 \%$ of students who are part of a sports community, $43 \%$ of students who are part of a music community, $47 \%$ of students who are part of a club community, and $40 \%$ of students who not part of any communities, indicating that those who are not involved in any of the listed community types are less likely to hang out with their families to relieve stress.

To look at another aspect, $19 \%$ of students who are part of a volunteering community "physically or verbally fight," $11 \%$ of students who are part of a sports community do so, $13 \%$ of the students who are involved in a music community do so, $11 \%$ of the students involved in clubs do so, and only $5 \%$ of students who are not involved in any of the previous types of communities do so. Significantly fewer individuals who are not part of volunteering, sport, music, of club communities physically or verbally fight to relieve stress.

Looking at this data, I deduce that those involved in volunteer communities and sports communities use more "social" coping mechanisms than those who are not involved with either volunteering, music, clubs, or sports. However, the findings also show that the difference in the percentage of students in volunteering and sports communities versus music and club communities in using "social" coping mechanisms is not significant enough to make a definitive claim, disproving the first part of my hypothesis. The difference in use of social coping mechanisms between those involved in any of the previous communities and none of them, however, is 34\%, which is a significantly large number. The case has thus been made that those involved in any type of community tend to have more social coping mechanisms than those who are not.

Part 2:

Students who are part of a volunteer or sports community are not worse at managing their stress than those who are not.

Table 2 shows a difference of 0.708 on the Coping Ability Scale for those who volunteer and those who do not, and a difference of -1.532 between those who are part of a sports community and those who are not. These numbers are not significant enough to indicate a true difference in stress management, disproving my hypothesis.

A related and notable trend is that those who are involved in a music community are both more stressed (by 3.124 points on the Coping Ability Scale) and worse at coping with that stress (by 2.832 points on the Coping Ability Scale) than those who are not. This can be observed from Table 2 and Figure 4. This could mean that those in the music community are worse at managing their stress compared to other communities. However, further research is required.

\section{Part 3:}

For the most part, the disparities in coping mechanisms between those who use different coping mechanisms based on their communities was not significant. There were not significant differences in the percentages of different communities using different coping mechanisms. However, some differences exist and are worth noting.

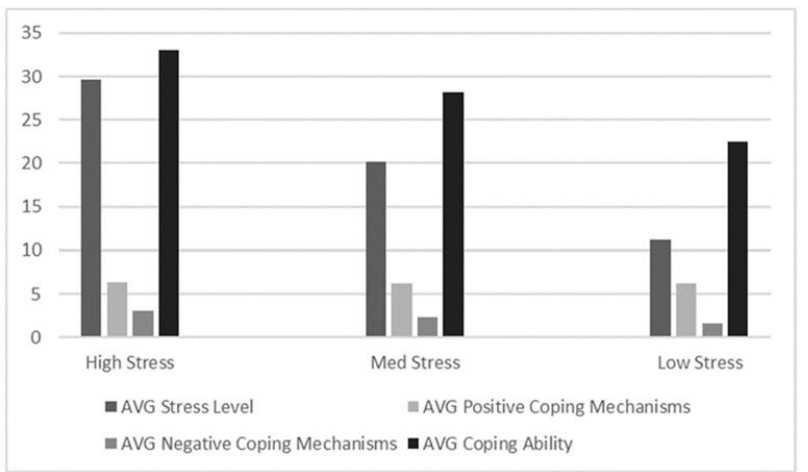

Fig. 8. Correlations between stress level (determined by the Perceived Stress Scale, where a score of 0 to 15 is considered low stress, 16 to 25 medium, and 26 to 40 high) and students' ability to cope with stress and the number of positive and negative coping mechanisms

For instance, $78 \%$ of those who are involved volunteering communities and $78 \%$ of those who are involved in sports communities "exercise" to relieve stress, while $58 \%$ of those in music communities do, $56 \%$ of those in club communities do, and $30 \%$ of those who are not part of any communities do. This means that significantly more people who are part of volunteer and sports communities exercise to relieve stress than those in other groups and a significant number of those who are not involved in any of the four types of communities do not exercise to relieve stress.

Another trend is that $66 \%$ of those involved in a music community play music to relieve stress while, on average, only $40 \%$ of members of the other communities play music to relieve stress.

Overall, there are a few disparities worth noting, but there were no overall trends in differences in mechanisms used by one community over another, other than what has been previously stated. This thus partially disproves my initial hypothesis.

\section{B. Reasoning Behind the Measures}

Based on my experience, volunteering, sports, music, and clubs are the four main categories that cover extracurriculars for high school students. One factor I did not consider is "job" because many students are involved in a workplace community as well.

For my measures I brainstormed and listed several common coping mechanisms. I had input from classmates to add or remove some of the mechanisms on my list and from my final list. I named each mechanism to be either positive or negative. I aimed for objectivity, naming coping mechanisms like "physically or verbally fighting" as negative and "exercise" as positive. However, I ultimately deemed "watch something" as a positive coping mechanism, "video games" as a negative, and 
"sexual activity (includes intercourse and masturbation)" as a positive, based on several scholarly articles [17], [18]. However, these coping mechanisms are subjective to each individual's situation and to what extent they are being done, so while I attempted to categorize them as "positive" or "negative"; this may be inaccurate for some individuals and their situations.

I used the Perceived Stress Scale for this, which has been used before and is an effective scale [14]. I used my own scale, the Coping Ability Scale, to measure the students' ability to cope with stress. I adapted this scale from an existing scale that was used in studies with children [15], [16]. The Coping Ability Scale and the coping mechanisms list served to identify how people in different communities coped with stress while the Perceived Stress Scale existed in case of a correlation, which there was. I asked students about their primary stressors in case it may be relevant during analysis, but I decided this study was more concerned with stress levels than specific stressors.

\section{Notable Trends}

Students who are more stressed (a higher score on the Perceived Stress Scale) were also worse at coping with their stress (a higher score on the Coping Ability Scale), as demonstrated in Figure 8. Additionally, students involved in all four types of communities were significantly more stressed than their peers (Figure 7). This data raises a theory that it is not what an individual does, but how much they do that influences both how stressed they are and how well they can cope with their stress, but this requires more research.

\section{Compared with Research in the Field}

Shahroom et al. performed a similar study, examining various coping strategies implemented by youth, but there are a few differences in our research methods [19]. Mainly, they looked at youth using physical activity as a coping mechanism; in other words, a specific strategy, while my study looked for trends in different strategies. Furthermore, Shahroom et al.'s sample population included high school students, as well as adults in their twenties and thirties. The study also included religious activity and sleeping as coping mechanisms which I did not include in my study, but which are helpful in noticing trends. While many of the strategies used in our studies were similar, our results primarily varied. Khan et al. determined that sleep was the primary coping mechanism used by youth overall as opposed to my results indicating that listening to music was the most used coping mechanism [20].

Khan et al. observed the correlations between stressors and coping mechanisms in university students, but focused on terrorism as the specific stressor and religion as the specific coping mechanism. They found that those who are better able to handle stress experience their stress to a lesser degree [20]. This aligns with my own findings, as seen in Figure 8. While their study was more focused than mine, and arguably yielded more precise results, my study provides a general perspective that also gives valuable insight. It is also worth noting that the sample population from Khan et al. were university students, an age range slightly older than my own.

\section{E. Implications and Limitations}

My study seems to offer a new direction for research: community as a factor of stress seems to be not as impactful of a variable as I initially presumed and the relationship between the level of stress and the ability to cope with stress in stressful situations requires further research.

Further research in this field would benefit youth across the nation as it would provide insight into how peers cope with stress, allowing for more detailed and specific intervention programs. The insight would aid school administrators as well.

A major limitation of my research is that I only included data collected from two schools, and that more than $80 \%$ of my data came from one school. In that school, the health teacher mandated that her students take it as part of their class curriculum. In the other school, the teacher made it optional and emailed it to her students. Furthermore, everything during my data collection process was self-reported and thus prone to error. I do want to make a note that those who are not involved in volunteer communities, sports communities, music communities, and club communities are not necessarily not involved in any sort of community at all-just the four major ones I investigated.

\section{Conclusion}

General community distinctions do not impact students' stress and coping mechanisms. More research into participation in specific clubs and communities and their impact on stress, perhaps using case studies and interviews, is required. However, differences in stress and coping mechanisms based on involvement in communities does exist. Correlations between workload, stress, and coping ability hold promise and require further investigation. Research on such topics have the potential to provide a better understanding of stress and coping among youth to find areas to target for intervention to promote healthy and successful coping mechanisms.

\section{References}

[1] S. W. Schwarz, "Adolescent Mental Health in the United States", in Improving the Odds for Adolescents Publications, 2009.

[2] M. Reykdal, "Social Emotional Learning K-12 Standards Adoption Statement," Apr. 2020,

[Online] Available:

https://www.k12.wa.us/sites/default/files/public/studentsupport/sel/pubd ocs/SEL \%20Standards\%20adoption\%20letter\%20signed.pdf

[3] "Stressor," in APA Dictionary of Psychology, 2020. [Online]. Available: https://dictionary.apa.org/stressor

[4] S. Taylor, "Coping Strategies," in Psychosocial notebook, 1998. [Online]. Available: https://macses.ucsf.edu/research/psychosocial/coping.php

[5] M. Cherewick, A. Kohli, M. M. Remy, et al., "Coping among traumaaffected youth: a qualitative study," in Conflict \& Health, vol. 9, no. 35, Nov. 2015.

[6] R.A. Vaughn-Coaxum, Y. Wang, J. Kiely, J. R. Weisz, and E.C. Dunn, "Associations Between Trauma Type, Timing, and Accumulation on Current Coping Behaviors in Adolescents: Results from a Large, Population-based Sample," in Journal of Youth \& Adolescence, vol. 47, no. 4 , pp. 842-858.

[7] P. Boxer, E. Sloan-Power, I. Mercado, \& A. Schappell, "Coping with Stress, Coping with Violence: Links to Mental Health Outcomes Among At-risk Youth," in Journal of Psychopathology \& Behavioral Assessment, vol. 34, no. 3, pp. 405-414, Apr. 2012.

[8] A.C. Woodman, M.R. Mailick, and J. S. Greenberg, "Trajectories of internalizing and externalizing symptoms among adults with autism 
spectrum disorders," in Development and Psychopathology, vol. 28, no. 2, pp. 565-581.

[9] E. Rosenberg, K. Burt, R. Forehand, and A. Paysnick, "Youth Self-Views, Coping with Stress, and Behavioral/Emotional Problems: The Role of Incremental Self-Theory," in Journal of Child \& Family Studies, vol. 25, no. 6 , pp. 1713-1723.

[10] M. Rosario, S. Salzinger, R. S. Feldman, and D. S. Ng-Mak, "Intervening Processes Between Youths' Exposure to Community Violence and Internalizing Symptoms Over Time: The Roles of Social Support and Coping," in American Journal of Community Psychology, vol. 41, no. 1/2, pp. 43-62, 2008.

[11] N. G. Harden and J. Cunningham, "The Impact of Racial Discrimination and Coping Strategies on Internalizing Symptoms in African American Youth," in Journal of Youth \& Adolescence, vol. 38, no. 4, pp. 532-543, Dec. 2008

[12] Y. Sanchez, S. Lambert, and M. C. Strickland, "Adverse Life Events, Coping and Internalizing and Externalizing Behaviors in Urban African American Youth," in Journal of Child \& Family Studies, vol. 22, no. 1, pp. 38-47.

[13] P. E. Jose and C. Huntsinger, "Moderation and Mediation Effects of Coping by Chinese American and European American Adolescents," in Journal of Genetic Psychology, vol. 166, no. 1, pp. 16-44, Aug. 2010.

[14] S. Cohen, and G. Williamson, "Perceived Stress in a Probability Sample of the United States," in S. Spacapan and S. Oskamp (Eds.), The Social Psychology of Health, Newbury Park, CA: Sage, 1988, pp. 31-67.

\section{Appendix A}

High School Stress and Coping Project Survey

The survey reads as follows:

\section{PAGE $1 / 5$}

Please type your full name below and fill out the consent form if you are interested in a follow-up interview (this does not bind you to participate in an interview). Otherwise, please write 'Anonymous' ".

Link to consent form: https://forms.gle/FnmZn7b4CPQdrQxi9

All of the questions in this survey are OPTIONAL. If you feel you cannot answer a question, do not feel pressured to do so.

o I understand

By clicking "I agree" below, I am attesting that I will do my best to answer the questions in this survey with honesty.

o I agree

\section{PAGE $2 / 5$}

What school are you enrolled in?

o Newport

o Interlake

o Sammamish

o Lake Washington

o Redmond

o Bear Creek

o Tesla STEM

o Bellevue Christian

o Eastlake

o Eastside Catholic

o Skyline

o Emerson

o Bothell

o Juanita

o Roosevelt

o Ballard

o Bush

o Garfield

o Franklin

o Issaquah

o Woodinville

o Inglemoor

o Ingraham

o Lakeside
[15] M. Wright, R. Banerjee, W. Hoek, C. Rieffe, and S. Novin, "Depression and social anxiety in children: Differential links with coping strategies," in Journal of Abnormal Child Psychology, vol. 38, no. 3, pp. 405-419, 2010.

[16] L.B.C. Pouw, C. Rieffe, L. Stockmann, and K. D. Gadow, "The link between emotion regulation, social functioning, and depression in boys with ASD. Research in Autism Spectrum Disorders," in Research in Autism Spectrum Disorders, vol. 7, no. 4, pp. 549-556, 2013.

[17] T. Ein-Dor, and G. Hirschberger, "Sexual healing: Daily diary evidence that sex relieves stress for men and women in satisfying relationships," in Journal of Social and Personal Relationships, vol. 29, no. 1, pp. 126-139, Jan. 2012.

[18] K. C. Madhav, S. P. Sherchand, and S. Sherchan, "Association between screen time and depression among US adults," in Preventive medicine reports, vol. 8, pp. 67-71, Aug. 2017.

[19] S. B. Shahroom, D. Ganapathy, and R. M. Visalakshi, "The perception of youth on physical activity to relieve stress," in Drug Invention Today, vol. 12, no. 6, pp. 1138-1142, June 2019.

[20] S. Khan, R. Sadia, and R. Sohail, "Resilience and Terrorism Catastrophizing: Mediating Role of Religious Coping Strategies," in Pakistan Journal of Psychological Research, vol. 33, no. 1, pp. 223-237, 2018.

What grade are you in?

o Freshman

o Sophomore

o Junior

o Senior

How old are you?

o 13

o 14

o 15

o 16

o 17

o 18

o 19

What gender do you identify as?

o Female

o Male

o Non-Binary

o Prefer not to say

o Other

What is your ethnicity?

o White

o Hispanic/Latino

o Black/African American

o Native American/American Indian/Alaskan Native

o Asian/Pacific Islander

o Other

How would you describe the income range of your family?

o Low

o Lower-middle

o Upper-middle

o High

Are you involved in any of the following extracurricular activities? (check all that apply)

$\square$ Music

$\square$ Sport

$\square$ Club

$\square$ Volunteering

If applicable, elaborate on your previous answer

e.g. if you are involved in music, please specify the type of music and location in which you practice. Be as specific as you can. 
Are you a member of the LGBTQ+ community?

o Yes

o No

o Maybe

Have you experiences mental/emotional challenges? If applicable, please briefly describe below.

\section{PAGE $3 / 5$}

In the last month, how often have you...

NeverRarely

Sometimes

Often

Very often

been upset because of something that happened unexpectedly?

$\square \square \square \square \square$

felt that you were unable to control the important things in your life?

$\square \square \square \square \square$

felt nervous and stressed?

$\square \square \square \square \square$ felt confident about your ability to handle your personal problems?

$\square \square \square \square \square$

felt that things were going your way?

$\square \square \square \square \square$

found that you could not cope with all the things you had to do?

$\square \square \square \square \square$

been able to control irritations in your life?

$\square \square \square \square \square$

felt you were on top of things?

been angered because of things that happened that were outside of your control?

$\square \square \square \square \square$

felt your difficulties piling up so high that you could not overcome them?

$\square \square \square \square \square$

How much do each of the following stress you out on a scale of 1 to 5 ?

Not stressful Not very stressful Somewhat Stressful Stressful

Very stressful

School

$\begin{array}{lllll}1 & 2 & 3 & 4 & 5\end{array}$

Job

$\begin{array}{lllll}1 & 2 & 3 & 4 & 5\end{array}$

Relationship with family members

$\begin{array}{lllll}1 & 2 & 3 & 4 & 5\end{array}$

Romantic relationships

$\begin{array}{lllll}1 & 2 & 3 & 4 & 5\end{array}$

Friendships

$\begin{array}{lllll}1 & 2 & 3 & 4 & 5\end{array}$

Financial prospects (money problems)

$\begin{array}{lllll}1 & 2 & 3 & 4 & 5\end{array}$

Religion/spirituality

$\begin{array}{lllll}1 & 2 & 3 & 4 & 5\end{array}$

Potential to influence others

$\begin{array}{lllll}1 & 2 & 3 & 4 & 5\end{array}$

Sexual life

$\begin{array}{lllll}1 & 2 & 3 & 4 & 5\end{array}$

Self-image/body image

$\begin{array}{lllll}1 & 2 & 3 & 4 & 5\end{array}$

Home life

$\begin{array}{lllll}1 & 2 & 3 & 4 & 5\end{array}$

Life skills and current knowledge

$\begin{array}{lllll}1 & 2 & 3 & 4 & 5\end{array}$

Medical issues

$\begin{array}{lllll}1 & 2 & 3 & 4 & 5\end{array}$

Ability to manage stress

$\begin{array}{lllll}1 & 2 & 3 & 4 & 5\end{array}$

Nutrition/food intake

$\begin{array}{lllll}1 & 2 & 3 & 4 & 5\end{array}$

Future

$\begin{array}{lllll}1 & 2 & 3 & 4 & 5\end{array}$

\section{PAGE $4 / 5$}

Ways I relieve stress (check all that apply):
$\square$ Exercise
$\square$ Do chores
$\square$ Use addictive drugs
$\square$ Work
$\square$ Do homework
$\square$ Listen to music
$\square$ Play music
$\square$ Cook
$\square$ Draw
$\square$ Vape
$\square$ Sing
$\square$ Use marijuana
$\square$ Drive
$\square$ Hang out with friends
$\square$ Spend time with family
$\square$ Eat
$\square$ Physically of verbally fight
$\square$ Isolate myself
$\square$ Stay alone in my room
$\square$ Get some space
$\square$ Watch something
$\square$ Binge eat
$\square$ Video games
$\square$ Read something
$\square$ Sexual activity (includes intercourse and masturbation)
$\square$ Other

How would you handle a stressful situation?

For example scenarios that may apply: Someone important in your life is yelling at you; you receive a bad grade; someone is being uncooperative. Please keep in mind to keep these general as well.

Not at all

Not often

Sometimes

Often All the time

I yell or shout to let off steam.

I worry about it.

I get help from someone I trust.

I try to think of different ways to solve the problem.

I tell someone I trust what happened.

I forget the whole thing.

I cuss or swear.

I do something to help me forget about it.

I get angry.

I throw or hit things.

I watch TV or read a book so I can take my mind of the problem

I ask someone for advice.

I tell myself it is not important.

I keep feeling afraid it will happen again.

I ignore the problem.

I think about it so much that I can't sleep.

\section{PAGE 5/5}

Would you be interested in doing a follow-up interview?

The follow-up interview would be an open-ended verbal interview on the phone, on a video-call, or in person. The follow-up survey would happen around mid to late February and would be 15 minutes long.

o Yes

o No

o Maybe

PAGE 5.5/5 (dependent upon answer in PAGE 5/5)

Please provide your contact for follow up for the survey:

Please provide whatever form of contact works for you (preferably email or phone number). 


\section{Appendix B}

High School Stress and Coping Project Consent Form The consent form reads as follows:

$$
\begin{array}{lll}
\text { !!!!! IMPORTANT } & \text { !!!!! } \\
\text { !!!!! PLEASE READ } & \text { !!!!! }
\end{array}
$$

\section{Information on the Project}

Hello, my name is Nithya Kemp and I am the primary researcher for this research project. In this study, I aim to understand what the stressors and coping mechanisms of youth across the Seattle Area are and how their community influences them. My intent is that the outcome of this project will be used by school administration and perhaps the State of Washington to direct their attention to youth who may require more assistance regarding their stressors or coping methods.

\section{Participation}

If you participate in this study, you will be asked to complete a survey which asks questions about you and your experience with stress, including your stressors and coping mechanisms. * You may also choose to have a one-on-one interview with me if you please.

TIME REQUIRED: The survey should take under 10 minutes (should not exceed 15 minutes) to complete, although the time needed may vary depending on the individual.

POTENTIAL RISKS: The primary content of this survey inquires about the user's experiences with stress and their coping mechanisms. If you experience moderate to severe mental health issues that may make your survey experience unpleasant or unsafe, it may not be a good idea for you to take this survey-especially if you believe thinking about stressors can cause you distress.
If you do come across a question that you feel you are unable to answer, you are under no obligation to answer it. If you do not answer sufficient number of questions, however, your survey results are at risk of being discarded.

BENEFITS: You will contribute to valuable research that may help struggling teenagers in the Seattle Area!

CONFIDENTIALITY (how confidentiality will be maintained): Your names will be discarded once I verify that you have signed this form. Unless you agree to be interviewed (which you can do by checking a box at the end of the survey if you chose to participate), your name will not be mentioned at all in the research paper itself. Even if you choose to participate in the interview, you can request to be anonymous. I will delete all digital files and shred and discard any papers regarding your information or data by July 1st, 2020 (other than the research paper itself).

If you have any questions, feel free to contact me or my advisor:

$\begin{array}{ll}\text { Nithya Kemp } & \text { s-kempn@bsd405.org } \\ \text { Robert Prufer } & \text { pruferr@bsd405.org }\end{array}$

*If you have any concerns regarding the content of the survey, please contact me using the above contacts.

\section{PLEASE TAKE NOTE:}

Participation in this study is completely voluntary. Please be aware that if you decide to participate, you MAY STOP PARTICIPATING AT ANY TIME and you may decide not to answer any specific question.

By typing my full name below, I am attesting that I have read and understood the information above, and I freely give my consent to participate. 